\title{
Establishment of Reference Ranges for Liver Biochemistry Tests in Children in Meru County, Kenya
}

\section{Kainyu RM ${ }^{\star}$, Njagi ENM, George $O$ and Kiruki S}

Department of Biochemistry and Biotechnology, Kenyatta University, Nairobi, Kenya

*Corresponding author: Kainyu RM, Department of Biochemistry and Biotechnology, Kenyatta University, PO Box 43844-00100 Nairobi, Kenya, Tel: +254-208711622; E-mail: njagieliud@yahoo.com

Rec date: January 01, 2018; Acc date: January 04, 2018; Pub date: January 11, 2018

Copyright: @ 2018 Kainyu RM, et al. This is an open-access article distributed under the terms of the Creative Commons Attribution License, which permits unrestricted use, distribution, and reproduction in any medium, provided the original author and source are credited.

\begin{abstract}
This study was aimed at determining the reference range values for eight liver function parameters that are routinely analyzed in the clinical chemistry laboratory of Meru Level 5 Hospital. The study was cross-sectional, population-based and carried out on the young population of ages one to seventeen years in Meru County, Kenya. A total of 768 samples were collected from the volunteers who participated in the study. Out of these, 740, comprising 360 females and 380 males that were found to be free from HIV, Hepatitis B and syphilis were used to construct the reference ranges. DRI - CHEM NX 500I Clinical Chemistry analyzer (Fujifilm, Europe) was used to analyze eight biochemical parameters. Determination of reference ranges was done in order to estimate the lower 2.5 and upper 97.5 percentiles of the distribution by use of parametric methods. The determined percentiles were considered the lower and upper reference limits respectively. Significant sex differences were observed in children reference values for total protein. Other parameters (alkaline phosphatase, gamma glutamyl transferase, direct bilirubin, total bilirubin, albumin, alanine aminotransferase, aspartate aminotransferase) did not show significant sex dependent differences. In conclusion, the findings of this study provide sex-specific reference range values for children from Meru County in Kenya. The study recommends the health care practitioners and facilities in the region under study to adopt the new reference values developed and for other regions in Kenya to carry out a similar study to determine their own reference values.
\end{abstract}

Keywords: Reference ranges; Liver; Sex

\section{Introduction}

Reference value refers to the value or test result obtained through observation or measurement of a particular type of analyte on an adequate number of individuals selected as representatives of the general population. The reference range is normally set as mean \pm 2 standard deviations and encompasses $95 \%$ of the presumably healthy group of population studied.

Clinicians order laboratory tests for a variety of reasons: screening for disease, diagnosis of disease, monitoring nous substances like electrolytes, determining prognosis, confirming a previous abnormal test, clinician education and medical legal purposes. When a test is used for disease screening, diagnosis or prognosis, the test result is normally compared with a normal range that is defined as usual value for a healthy population [1].

Clinical medicine practice requires that laboratory test results from a patient are compared against some pre-determined standard results so as to determine whether the patient is "normal" or is suffering from a certain pathological condition. Laboratories should therefore report test results along with the corresponding reference intervals since physicians and other health practitioners make their medical decisions based on available, appropriate and reliable reference intervals.

Medical decision is also backed by the information gathered during medical interview as well as clinical examination. In the laboratory, the word "normal" has several meanings other than being used to describe the usual range of laboratory data for healthy populations. It is used to describe the health of individuals and is also synonymously used with the "Gaussian" when the shapes of distributions are described.

Factors specified when reference values are established include: (1) Make up of reference population in terms of age, gender and genetic and socio-economic factors. (2) The inclusion and exclusion criteria used. (3) The conditions, both physical and physiological under which the reference population is sampled and studied. (4) The procedure of collecting the specimen, including how the subject was prepared before collection and (5) the method of analyzing the sample used giving details of its precision and accuracy [2].

Since measured biochemical parameters are affected not only by individuals' factors such as age, sex, diet but also by population and ecological factors such as ethnic background, climate, geography and altitude, they are found to vary not just between individuals but between populations as well [3].

Presently most clinical laboratories in Meru County as well as the whole republic of Kenya use reference values as indicated on reagent kits or those that are published in medical and laboratory textbooks to interpret patient results. This can be of a grave mistake bearing in mind that parameters vary from region to region [4].

The patient's results can also vary due to the methods used in analyzing, that is either manual or by automation. Thus, it is important that clinical chemistry laboratories determine reference values that are specific to the populations they serve. To ensure the results are accurate and precise, there is need to establish reference values following the standard operating procedures (SOP) [5].

This study is designed to establish health associated reference ranges to be used by clinical chemistry laboratories in the area of study and 
determine whether there are significant variations between them and those used in the facilities as provided by the reagent manufacturers.

\section{Materials and Methods}

\section{Selection of reference population}

The reference population was selected based on the guidelines described by the CLSI, 2000. According to the guidelines, the reference individuals selected should be closely similar to the patient population under study and should be of the same age to be clinically significant. A priori sampling method was employed in this study. This is where selection of an adequate number of subjects who serve as reference individuals takes place first and then samples are drawn for analysis. Children between 1-17 years of age were randomly selected after holding community meetings with the leaders and parents/guardians to explain the objectives of the study.

\section{Study design}

This was a population based cross-sectional study involving 740 healthy male and female subjects of age 1 to 17 years.

\section{Specimen collection}

$5-\mathrm{ml}$ of blood was collected by venipuncture using a 23-gauge butterfly needle with a 5-ml syringe after sterilizing the area with $70 \%$ alcohol and dispensed into a plain vacutainer (without anticoagulant) tube then transferred in $2 \mathrm{ml}$ tubes (vacutainer TM, Becton Dickinson, Franklin Lakes, NJ). Each of the tubes containing the specimens was labeled with the subject's name, the study number and the date of collection of the sample. The specimens were arranged in Styrofoam cool boxes at $4^{\circ} \mathrm{C}$ and covered to protect them from heat and sunlight, awaiting transportation to the main analytical center.

\section{Specimen transportation, processing and storage}

The specimens collected in the field were ferried from the point of collection to the clinical chemistry laboratory of Meru Level Five Hospital in cool boxes within two hours of collection at room temperature. Upon arrival at the clinical chemistry laboratory, the blood specimens were centrifuged at a speed of $3000 \mathrm{rpm}$ for two minutes to obtain serum. The serum was transferred to separate tubes labeled with subject's identification details. Laboratory analysis was done as soon as possible to avoid loss of sample viability. If analysis was not done immediately, the samples were stored at $-20^{\circ} \mathrm{C}$ for a period not exceeding seven days.

\section{Laboratory analysis}

The samples were analyzed for eight liver function tests. These analytes were: total protein, albumin, alanine aminotransferase (ALT), aspartate aminotransferase (AST), alkaline phosphatase (ALP), gamma glutamyl transferase (GGT), direct bilirubin and total bilirubin. All the assays were carried out as per the standard operating procedures (SOPs) found at the hospital laboratory.

\section{Equipment for analysis}

The equipment used for the sample analysis was DRI-CHEM NX500i, a dry chemistry clinical analyzer that is able to carry out a wide range of chemical tests in a single run.

\section{Reagent preparation}

The machine uses coded slides that are commercially acquired and specifically tailored for the equipment. Each slide is impregnated with reagent for a specific parameter and is labeled clearly. The slides for the various tests being carried out are inserted in the machine along with the sample and once the patient details are entered and the machine set to start, the tests run automatically and a print-out of the results is obtained.

\section{Calibration of the test}

In order make sure to that the values obtained from the samples assayed were accurate and precise, the analyzer was set to perform a calibration procedure for the tests. Calibration was done by passing the QC card through the QC card reader whenever slides from a new lot number were being used.

\section{Quality Control (QC) materials}

Assayed multisera whose values were predetermined and known (normal) were used for the quality control of all the analyses done. The multisera were supplied in lyophilized form and were reconstituted when being used as per the manufacturer's guidelines. Internal quality control assessment was done by analyzing the multisera daily or at any other time as deemed necessary.

\section{Results}

From the study, it was noted that reference values that are used in management of children differ with those that were established, therefore indicating that there is need to have each laboratory determine reference values that are specific to its population as required by the CLSI. 740 samples were analyzed in this study out of the 768 initially collected for the study. 28 samples were excluded because $6(21.4 \%)$ of them were HIV positive and $22(78.6 \%)$ were hemolyzed. Reference values for eight biochemical parameters were established for both males and females of age 1 to 17 years.

Construction of these reference values was by use of the 2.5th and 97.5th percentiles as lower and upper limits respectively and at $95 \%$ confidence interval. This is in accordance with CLSI guidelines for reference interval determination [3].

Table 1 shows sex specific reference values for every parameter depending on the $\mathrm{p}$-values obtained from the difference between male and female subjects. Significant sex differences were observed in TP $(\mathrm{p}=0.039)$. In the course of the study, control value results as well as the standard deviation (SD) from the value were recorded every day.

\begin{tabular}{|l|l|l|l|l|l|l|}
\hline $\begin{array}{l}\text { Analyte } \\
\text { (unit) }\end{array}$ & Sex & N & Mean & Percentiles & $\begin{array}{l}\text { Reference } \\
\text { Value }\end{array}$ & RI \\
\hline
\end{tabular}


Citation: Kainyu RM, Njagi ENM, George O, Kiruki S (2018) Establishment of Reference Ranges for Liver Biochemistry Tests in Children in Meru County, Kenya. Clin Med Biochem 4: 138. doi:10.4172/2471-2663.1000138

Page 3 of 5

\begin{tabular}{|c|c|c|c|c|c|c|c|c|c|}
\hline & & & & 2.5th & 97.5th & & $F$ value & Sig & \multirow{4}{*}{0.949} \\
\hline \multirow{3}{*}{$\begin{array}{l}\text { ALB } \\
(g / L)\end{array}$} & M & 380 & 38.47 & 27.98 & 48.96 & $27.98-48.96$ & 20.98 & \multirow[t]{3}{*}{0.120} & \\
\hline & $\mathrm{F}$ & 360 & 38.56 & 28.62 & 48.50 & $28.62-48.50$ & 19.88 & & \\
\hline & $M \& F$ & 740 & 38.51 & 28.30 & 48.72 & $28.30-48.72$ & 20.42 & & \\
\hline \multirow{3}{*}{$\begin{array}{l}\text { AST } \\
(\mathrm{U} / \mathrm{L})\end{array}$} & M & 380 & 32.07 & 10.16 & 54.30 & $10.16-54.30$ & 44.14 & \multirow[t]{3}{*}{0.167} & \multirow[t]{3}{*}{0.919} \\
\hline & $\mathrm{F}$ & 360 & 32.39 & 5.65 & 58.93 & $5.65-58.93$ & 53.28 & & \\
\hline & $M \& F$ & 740 & 32.20 & 9.92 & 54.60 & $9.92-54.60$ & 44.68 & & \\
\hline \multirow{3}{*}{$\begin{array}{l}\text { ALP } \\
(U / L)\end{array}$} & M & 380 & 87.97 & 61.63 & 114.31 & $61.63-114.31$ & 52.68 & \multirow[t]{3}{*}{0.461} & \multirow[t]{3}{*}{0.709} \\
\hline & $\mathrm{F}$ & 360 & 87.97 & 58.21 & 114.23 & $58.21-114.23$ & 56.02 & & \\
\hline & M\&F & 740 & 87.48 & 61.63 & 114.31 & $61.63-114.31$ & 52.68 & & \\
\hline \multirow{3}{*}{$\begin{array}{l}\text { ALT } \\
(\mathrm{U} / \mathrm{L})\end{array}$} & M & 380 & 32.23 & 11.18 & 57.20 & $11.18-57.20$ & 46.02 & \multirow[t]{3}{*}{0.896} & \multirow[t]{3}{*}{0.443} \\
\hline & $\mathrm{F}$ & 360 & 32.29 & 10.24 & 56.84 & $10.24-56.84$ & 46.6 & & \\
\hline & M\&F & 740 & 33.11 & 10.75 & 57.80 & $10.75-57.80$ & 47.05 & & \\
\hline \multirow{3}{*}{$\begin{array}{l}\text { D-BIL } \\
(\mu \mathrm{mol} / \mathrm{L})\end{array}$} & $M$ & 380 & 2.13 & 0.43 & 3.53 & $0.43-3.53$ & 3.1 & \multirow[t]{3}{*}{2.640} & \multirow[t]{3}{*}{0.152} \\
\hline & $\mathrm{F}$ & 360 & 2.20 & 0.21 & 4.19 & $0.21-4.19$ & 3.98 & & \\
\hline & $\mathrm{M} \& \mathrm{~F}$ & 740 & 2.17 & 0.46 & 3.88 & $0.46-3.88$ & 3.42 & & \\
\hline \multirow{3}{*}{$\begin{array}{l}\text { T-BIL } \\
(\mu \mathrm{mol} / \mathrm{L})\end{array}$} & M & 380 & 42.17 & 12.98 & 71.78 & $12.98-71.78$ & 58.8 & \multirow[t]{3}{*}{0.158} & \multirow[t]{3}{*}{0.924} \\
\hline & $\mathrm{F}$ & 360 & 42.82 & 12.19 & 73.45 & $12.19-73.45$ & 61.26 & & \\
\hline & M\&F & 740 & 42.48 & 12.6 & 72.56 & $12.6-72.56$ & 59.96 & & \\
\hline \multirow{3}{*}{$\begin{array}{l}\text { TP } \\
(\mathrm{g} / \mathrm{L})\end{array}$} & M & 380 & 43.25 & 30.78 & 55.72 & $30.78-55.72$ & 24.94 & \multirow[t]{3}{*}{2.809} & \multirow[t]{3}{*}{0.039} \\
\hline & $\mathrm{F}$ & 360 & 42.26 & 29.95 & 54.57 & $29.95-54.57$ & 24.62 & & \\
\hline & M\&F & 740 & 42.77 & 30.38 & 55.18 & $30.38-55.18$ & 24.8 & & \\
\hline \multirow{3}{*}{$\begin{array}{l}\text { GGT } \\
(\mathrm{U} / \mathrm{L})\end{array}$} & M & 380 & 73.58 & 18.82 & 128.34 & $18.82-128.34$ & 109.52 & \multirow[t]{3}{*}{0.399} & \multirow[t]{3}{*}{0.753} \\
\hline & $\mathrm{F}$ & 360 & 68.10 & 8.44 & 127.76 & $8.44-127.76$ & 119.32 & & \\
\hline & M\&F & 740 & 70.92 & 13.51 & 128.33 & $13.51-128.33$ & 114.82 & & \\
\hline
\end{tabular}

Table 1: Reference values by Sex for ALB, AST, ALP, ALT, D-BIL, T-BIL, TP and GGT. Results are given as mean values for the number of subjects in column $\mathrm{N}$. The difference in sex is significant at $\mathrm{p}<0.05$; Sig=significance; $\mathrm{RI}=$ reference interval.

Table 2 compares reference range values established with those found in the literature. This was done by comparing the values for the lower and upper reference limits as well as the interval values for each analyte. From the study, it was noted that significant differences exist between the reference ranges developed and those in use at the hospital. Out of the eight parameters studied, five of them did not have distinct values for adults and children and the same reference values were found to be used when interpreting test results for both children and adults.

\begin{tabular}{|c|c|c|c|c|c|c|c|}
\hline \multirow[t]{3}{*}{ Parameter/Unit } & \multicolumn{5}{|c|}{ Established Reference Intervals } & \multicolumn{2}{|c|}{ Literature Reference Values } \\
\hline & \multirow[t]{2}{*}{ Male } & \multirow[t]{2}{*}{ Female } & \multicolumn{3}{|c|}{ Male and Female } & \multirow[t]{2}{*}{ Mean values } & \multirow[t]{2}{*}{ RI } \\
\hline & & & Lower limit & Upper limit & $\begin{array}{l}\text { Reference } \\
\text { Interval }\end{array}$ & & \\
\hline ALB $(g / L)$ & $27.98-48.96$ & $28.62-48.50$ & 28.3 & 48.72 & 20.42 & $30-48$ & 18 \\
\hline $\operatorname{ALP}(U / L)$ & $61.63-114.31$ & $58.21-114.23$ & 61.63 & 114.31 & 52.68 & $47-406$ & 359 \\
\hline
\end{tabular}


Page 4 of 5

\begin{tabular}{|l|l|l|l|l|l|l|l|}
\hline ALT (U/L) & $11.18-57.20$ & $10.24-56.84$ & 10.75 & 57.8 & 47.05 & $0-50$ & 50 \\
\hline AST (U/L) & $10.16-54.30$ & $5.65-58.93$ & 9.92 & 54.6 & 44.68 & $0-50$ & 50 \\
\hline D-BIL( $\mu \mathrm{mol} / \mathrm{L})$ & $0.43-3.53$ & $0.21-4.19$ & 0.46 & 3.88 & 3.42 & 53.4 & 3.4 \\
\hline T-BIL ( $\mu \mathrm{mol} / \mathrm{L})$ & $12.98-71.78$ & $12.19-73.45$ & 12.6 & 72.56 & 59.96 & $1.7-21$ & 19.3 \\
\hline GGT(U/L) & $18.82-128.34$ & $8.44-127.76$ & 13.51 & 128.33 & 114.82 & $1.0-132$ & 131 \\
\hline TP $(\mathrm{g} / \mathrm{L})$ & $30.78-55.72$ & $29.95-54.57$ & 30.38 & 55.18 & 24.8 & $33-56$ & 23 \\
\hline
\end{tabular}

Table 2: Comparison of Established Biochemical Parameters of children 1-17 years with those in literature.

ALT, AST and ALB had both adult and children values, but these were found to be significantl differen from those established in the study. All the parameters studied except ALB portrayed difference in the reference range values obtained. ALT, AST, ALP, GGT and T-BIL all showed higher lower reference range limits than those of the manufacturers. ALT and AST had higher upper reference range limits as compared to those of manufacturers.

Th lower reference range limits of the enzymes ALT and AST were observed to be as high as ten times more than the manufacturer's. Th enzyme ALP showed a significantl higher lower limit and a significantl lower upper limit. Thus the reference interval for ALP was significantl shorter compared to that of manufacturer's. Thi phenomenon was also observed in GGT.

\section{Discussion}

Th results of this study provide the pioneer clinical chemistry reference ranges for the population of 1 to 17 years in Meru County, Kenya using 740 samples, 380 males and 360 females. Th number of participants in each category was more than the minimum number of 120 participants per subgroup required to determine reference ranges as recommended by CLSI 2000. Th tests were done using the same analytical methods and results expressed in the same units as those found in literature for easy comparisons.

External and internal quality control methods were closely followed and monitored throughout the study in addition to following the SOP at Meru Level Five Hospital [6].

In the study, it was established that there exist no reference ranges in Meru County for children and adolescents of 1-17 years for fiv out of the eight parameters studied. During clinical trials, this group of the population was found to be considered together with the adult population.

Out of the eight parameters studied only three were found to have reference ranges specifi to children, though the ages covered by the reference values used are not defined Thes parameters include ALT, AST and ALB. Ther were no reference range values available for TBIL, D-BIL, ALP, GGT and TP therefore the reference values developed in this study were compared against those for the adult population available.

Assuming that adults and children exhibit the same reference, ranges is a big mistake since reference ranges are known to vary with age among many other factors. Most studies carried out in Africa show reference intervals for direct bilirubin and albumin that are similar with those published from populations derived from the United States [7]. However, certain parameters have upper reference limits that are significantl higher. A good example of such a parameter is total bilirubin; T-BIL (manufacturer's: $1.7-2.1 \mu \mathrm{mol} / \mathrm{L}$; established: 12.6-72.56 $\mu \mathrm{mol} / \mathrm{L})$.

Th reason for these high T-BIL levels in the African populations may be due to RBC hemolysis as a result of malnutrition, physical exertion or malaria infection, conditions that are predominant in sub Saharan Africa. However, even within the African continent, disparities in theses parameters are observed because of large difference in climate, location, diet and human genetics [8].

Male adolescents had higher values for ALT, D-BIL, AST, TP and TBIL than female adolescents. Thes difference in sex were particularly significan for T-BIL and TP. AST was found to have significan differenc as the age of the child progressed. It is known that muscle mass affect AST, therefore the difference observed in this category of the population could be as a result of the production of this metabolite by male children's developed muscles.

Th sex differenc observed in serum TP in this study contrasts the one found in literature where males and females have the same reference values but agrees with the study done in Rwanda for adult humans [6]. ALB, ALT, AST, T-BIL and D-BIL have demonstrated higher values compared to manufacturers' ranges. Thi could be due to difference in diet, genetics and analytical methods. Males had higher values of GGT than females; this could be as a result of extra production of the enzyme from the prostate gland in males as compared to females who lack the organ.

Thi result was reported in studies carried out in other East African states $[9,10]$. ALT and AST have demonstrated higher values for both lower and upper reference values compared to those of manufacturer's range and other locations (ALT: 10.75-57.8 U/L; 0-50 U/L; AST: 9.92-54.6 U/L; 0-50 U/L). Differen lifestyles and genetic composition of the population could also explain the difference [11].

Generally, reference ranges have been shown to vary between differen populations due to difference in genetics, physical, environmental and socio-economic conditions and diet [12]. Th reference values for the parameters analyzed in this study diffe from those used to service the population. Thi clearly indicates the necessity to determine sex and age-based reference values for specifi populations instead of taking a set of reference values determined for one population and use them on another population. Thi will decrease the frequency of values reported as abnormal in otherwise healthy children and adolescents. 
Citation: Kainyu RM, Njagi ENM, George O, Kiruki S (2018) Establishment of Reference Ranges for Liver Biochemistry Tests in Children in Meru County, Kenya. Clin Med Biochem 4: 138. doi:10.4172/2471-2663.1000138

Page 5 of 5

\section{Conclusion}

From the study it was observed that no reference ranges are available for the study population in Meru County, Kenya and physicians and other health workers rely on adult values available from some Caucasian populations to interpret laboratory results for this group of population. This is a grave mistake because serum biochemistry parameters are known to vary with age, thus adult values cannot adequately represent children reference ranges. The importance of serum biochemistry normal ranges in the diagnosis and monitoring of disease cannot be underestimated; therefore, establishment and use of local reference ranges should be encouraged because it enhances patient care and health research. The results of the study show that reference values obtained vary with those from literature and those that are used at Meru Level Five Hospital.

The upper limits of serum transaminases, bilirubin, total protein and albumin for the children sampled in this study were higher than those from the Caucasian children. Significant sex- specific differences were observed in TP $(p=0.039)$. Most parameters like ALP had a much shorter reference range compared to that found for Caucasian population (Established: 61.63-114.31 U/L; Manufacturer's: 47-406 $\mathrm{U} / \mathrm{L})$. This clearly indicates the need to determine population specific ranges instead of using a general range developed using a different population. There was little, or no information found in literature for this population thus comparisons were done with those of adult populations. This was also observed in the clinical setting for most of the biochemical parameters studied, with adult values being used to interpret the results for this group of the population.

Clearly, similar studies of children in Africa should be carried out so as to broaden the present findings thus enabling improved care and conduct of clinical trials. Population-specific reference ranges/values obtained will be useful to achieve accurate, clinically relevant results that will provide true information about the patient's state of health in the region.

\section{References}

1. Harris EK, Cooil BK, Shakarji G, Williams GZ (1980) On the use of statistical models of within-person variation in long-term studies of healthy individuals. Clinical Chemistry 26: 383-391.
2. Grasbeck R, Siest AG, Wilding P, Williams GZ, Whitehead TP (1979) Determination of Reference Values In: Bishop ML (Ed), Clinical Chemistry: Principles, Procedures and Correlations, 2nd edn. Philadelphia, Lippincott Company, pp: 70-75.

3. Villanova PA (2000) National Committee for Clinical Laboratory standards: how to define, determine and utilize reference intervals in the clinical laboratory: proposed guidelines.

4. Waithaka SK, Njagi EN, Ngeranwa JN, Kigondu CS (2009) Reference ranges for some biochemical parameters in adult Kenyans. International Journal of Health Research 2: 259-266.

5. Ichihara K, Itoh Y, Lam CW, Poon PM, Kim JH, et al. (2008) Sources of variation of commonly measured serum analytes in 6 Asian cities and consideration of common reference intervals. Clinical Chemistry 54: 356-365.

6. Gahutu JB, Wane J (2006) Reference values for serum protein and electrolyte study from Rwanda. East African Medical Journal 83: 64-67.

7. Zeh C, Amornkul PN, Inzaule S, Ondoa P, Oyaro B, et al. (2011) Population-based biochemistry, immunologic and hematological reference values for adolescents and young adults in a rural population in Western Kenya. PLOS One 6: e21040.

8. Zeh CE, Odhiambo CO, Mills LA (2012) Laboratory reference intervals in Africa. In Blood Cell-An Overview of Studies in Hematology. InTech.

9. Saathoff E, Schneider P, Kleinfeldt V, Geis S, Haule D, et al. (2008) Laboratory reference values for healthy adults from southern Tanzania. Tropical Medicine \& International Health 13: 612-625.

10. Eller LA, Eller MA, Ouma B, Kataaha P, Kyabaggu D, et al. (2008) Reference intervals in healthy adult Ugandan blood donors and their impact on conducting international vaccine trials. PLOS One 3: e3919.

11. Manolio TA, Burke GL, Savage PJ, Jacobs DR, Sidney S, et al. (1992) Sexand race-related differences in liver-associated serum chemistry tests in young adults in the CARDIA study. Clinical Chemistry 38: 1853-1859.

12. Koram KA, Addae MM, Ocran JC, Adu-Amankwah S, Rogers WO, et al. (2007) Population based reference intervals for common blood haematological and biochemical parameters in the Akuapem north district. Ghana Medical Journal 41. 